Article

\title{
Molecular Insights into Sequence Distributions and Conformation-Dependent Properties of High-Phenyl Polysiloxanes
}

\author{
Lin Zhu ${ }^{1}$, Xiao Cheng ${ }^{1}{ }^{1}$, Wenlu Su ${ }^{1}$, Jiaxin Zhao ${ }^{1}$ and Chuanjian Zhou ${ }^{1,2, *(\mathbb{D})}$ \\ 1 School of Materials Science and Engineering, Shandong University, Jinan 250061, China; \\ zl170316@163.com (L.Z.); chengxiao@sdu.edu.cn (X.C.); 17853140550@163.com (W.S.); \\ zhonghengzjx@163.com (J.Z.) \\ 2 Key Laboratory of Special Functional Aggregated Materials, Ministry of Education, Jinan 250061, China \\ * Correspondence: zhouchuanjian@sdu.edu.cn; Tel.: +86-88369600
}

Received: 27 October 2019; Accepted: 24 November 2019; Published: 2 December 2019

\begin{abstract}
The excellent performance and wide applications of phenyl polysiloxanes are largely due to their phenyl units and monomer sequences. However, the relationship between molecular structure and material properties has not been explicitly elucidated. In this work, the sequence distribution and microstructure of random copolymers were quantitatively investigated by means of a molecular dynamics (MD) simulation combined with experimental verification. The results of ${ }^{29} \mathrm{Si}$ NMR showed that the large number of phenyl units not only shortened the length of the dimethyl units, but also significantly increased the proportion of consecutive phenyl units. The simulation results indicated the attraction between adjacent phenyl groups that were effectively strengthened intra- and intermolecular interactions, which determined the equilibrium population of conformations and the dynamics of conformational transitions. Furthermore, the evolution of bond angle distribution, torsion distribution, and mean-squared displacements (MSD) shed light on the conformational characteristics that induce the unique thermodynamics properties and photophysical behavior of high-phenyl polysiloxanes. Differential scanning calorimetry (DSC), dynamical mechanical analysis (DMA), spectrofluorimetry, and laser scanning confocal microscopy (LSCM) were performed to verify the conclusions drawn from the simulation. Overall, the complementary use of MD simulations and experiments provided a deep molecular insight into structure-property relationships, which will provide theoretical guidance for the rational design and preparation of high-performance siloxanes.
\end{abstract}

Keywords: phenyl polysiloxane; sequence distribution; molecular dynamics simulation; dynamic mechanical property; photophysical property

\section{Introduction}

Phenyl polysiloxanes, i.e., copolymers with incorporated of methylphenyl units ( $\mathrm{MePhSiO})$ or diphenyl units $\left(\mathrm{Ph}_{2} \mathrm{SiO}\right)$ in dimethylsiloxane $\left(\mathrm{Me}_{2} \mathrm{SiO}\right)$, possess a number of excellent characteristics including low-temperature flexibility, high-temperature stability, climate resistance, and maintaining superior mechanical properties over a wide temperature range [1,2]. Therefore, phenyl polysiloxanes in the form of oil, rubber, and resin have been widely used as sealants, adhesives, lubricants, insulating materials, and so forth [3]. Their performance and applications depend not only on the type of monomers, but also on the content of phenyl units and monomer sequences. For example, Liangliang $\mathrm{Qu}$ et al. reported that the incorporation of $\mathrm{Ph}_{2} \mathrm{SiO}$ units disordered the crystallization of the polydimethylsiloxane (PDMS) component, and that the maximum sequence length of $\mathrm{Me}_{2} \mathrm{SiO}$ units required for the copolymer to be amorphous was 11 [4]. Recently, Alisa Zlatanic et al. showed that the 
random introduction of $3.9 \mathrm{~mol} \%$ of $\mathrm{MePhSiO}$ units or $3.6 \mathrm{~mol} \%$ of $\mathrm{Ph}_{2} \mathrm{SiO}$ units was sufficient to completely eliminate the crystallization, which endows copolymers with excellent low-temperature properties [5,6]. Chyuan Chou et al. reported that the thermal stability of copolymers was significantly improved with incorporating $\mathrm{Ph}_{2} \mathrm{SiO}$ units, and different monomer sequences provided independent operational control for preparing materials with specific thermal property requirements [7]. Fengmei Yu et al. reported that the loss tangent $(\tan \delta)$ peak area and glass transition temperature $\left(T_{\mathrm{g}}\right)$ of random copolymers increased linearly with an increase in the number of $\mathrm{Ph}_{2} \mathrm{SiO}$ units, which indicated that a better damping property could be obtained with higher phenyl contents [8]. Despite the progress made by experiments such as those as mentioned above, the interaction mechanisms, microstructures, and conformational transformations of copolymers are rarely reported; this is especially the case for those with high phenyl units content (the ratio of phenyl to silicon $>30 \mathrm{~mol} \%$ ), in which the sequence distributions and interactions are more complicated.

In addition, phenyl polysiloxanes exhibit a characteristic UV absorption and have excellent optical performance, i.e., high refractive index and good radiation hardness. The conformational states and dynamics of the backbone play a significant role in the excimer emissions, and the fluorescence behavior can be modified by changing the content and distribution of phenyl units [9-11]. The intramolecular interaction of phenyl groups in dilute solutions has been the object of extensive studies [12-14]. However, detailed information about the photophysical properties in the solid state is still lacking; such knowledge may be unveiled with the aid of simulation technology.

Molecular dynamics (MD) simulation provides a powerful and intuitive method to probe the structure-property relationships of polymer systems, which not only provide a reasonable interpretation of the experimental results, but also predict the properties of the material to some extent [15-21]. A great deal of effort has been made with MD simulations combining theoretical calculations to investigate the distribution of isomeric conformations, unperturbed dimensions, blend compatibility, and interfacial dynamics [22-27]. However, to the best of our knowledge, a systematic study of the sequence distributions and conformational properties of polysiloxanes is currently not available.

In view of the above, the current work aims to reveal the structure-properties relationship of high-phenyl polysiloxanes at the atomic level. Two copolymers, i.e., poly(dimethyl-co-methylphenyl) siloxane (PDMS-co-PMPS) and poly(dimethyl-co-diphenyl)siloxane (PDMS-co-PDPS), were prepared by ring-opening polymerization, and the triad monomer sequences were quantitatively calculated by ${ }^{29} \mathrm{Si}$ NMR. An attempt was made to correlate the sequence distributions and conformational characteristics with dynamic mechanical properties and photophysical behavior by performing MD simulations. For comparison, polydimethylsiloxane (PDMS) was also studied. Furthermore, differential scanning calorimetry (DSC), dynamic mechanical analysis (DMA), spectrofluorometry and laser scanning confocal microscopy (LSCM) were conducted to confirm the conclusions obtained from the simulations. Taking a closer look at the sequence distribution and microstructure is of great significance for understanding the mechanism of copolymerization, explaining experimental phenomena, and designing molecular structures with specific properties.

\section{Materials and Methods}

\subsection{Materials and Samples Preparation}

Chemicals of the highest purity level available were obtained from Sigma-Aldrich (Shanghai, China), and were used without further purification. Octamethylcyclotetrasiloxane $\left(\mathrm{D}_{4}\right)$, methylphenylcyclosiloxanes ( $\mathrm{D}_{\mathrm{n}}$ MePh , a commercially available mixture of $n=3,4,5$ derivatives), octaphenylcyclotetrasiloxane $\left(\mathrm{D}_{4}{ }^{\mathrm{Ph} 2}\right)$ and 1,3,5,7-tetramethyl-1,3,5,7-tetravinyl-cyclotetrasiloxane $\left(\mathrm{D}_{4}{ }^{\mathrm{MeVi}}\right)$ were obtained from Hubei Jusheng Technology Co., Ltd. (Tianmen, China). PDMS, PDMS-coPMPS, and PDMS-co-PDPS were synthesized via ring-opening equilibrium polymerization with a tetramethylammonium hydroxideas catalyst $[5,6]$. All products were fractionated by precipitation in toluene-methanol as a solvent-precipitant system at room temperature to eliminate monomer 
impurities. The molecular structures of the three involved polysiloxanes are shown in Scheme 1, and the basic physical properties (Figure A1, Figure A2 in Appendix A) are presented in Table 1.

PDMS was mixed on mills with 2,5-Dimethyl-2,5-di(tert-butylperoxy)hexane, then vulcanized in a press at $170{ }^{\circ} \mathrm{C}$ for $20 \mathrm{~min}$. PDMS-Co-PMPS and PDMS-co-PDPS were mixed on mills with 2,4-dichlorobenzoyl peroxide and vulcanized in a press at $135^{\circ} \mathrm{C}$ for $20 \mathrm{~min}$ and $40 \mathrm{~min}$, respectively. All samples were subjected to two-stage vulcanization in an oven at $200{ }^{\circ} \mathrm{C}$ for $4 \mathrm{~h}$. It should be noted that there was no filler in all the vulcanized samples.

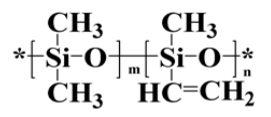

PDMS

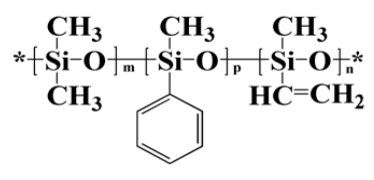

PDMS-co-PMPS

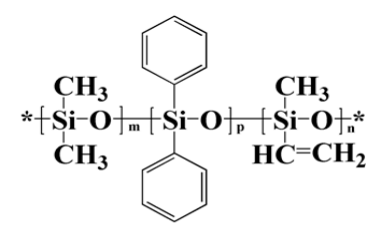

PDMS-co-PDPS

Scheme 1. Molecular structures of involved polysiloxanes.

Table 1. The basic physical properties of the involved polysiloxanes.

\begin{tabular}{cccc}
\hline Sample & $\mathbf{T}_{\mathbf{g}}\left({ }^{\circ} \mathbf{C}^{(\mathbf{a})}\right.$ & $\mathbf{M}_{\mathbf{w}}(\mathbf{k g} / \mathbf{m o l})^{(\mathbf{b})}$ & PDI $^{(\mathbf{c})}$ \\
\hline PDMS & -124 & 342.1 & 1.71 \\
PDMS-co-PMPS & -90 & 426.4 & 2.20 \\
PDMS-co-PDPS & -59 & 305.9 & 1.88 \\
\hline
\end{tabular}

(a) $T_{\mathrm{g}}$ denotes the glass transition temperature, measured by DSC at $50 \%$ transition; (b) $M_{\mathrm{W}}$ denotes the molecular weight molar mass, measured by GPC in THF; (c) PDI denotes the polydispersity index, PDI $=M_{\mathrm{w}} / M_{\mathrm{n}}$.

\subsection{Characterization}

NMR spectra were recorded on a Bruker AVANCE500 spectrometer for ${ }^{29} \mathrm{Si}$ and ${ }^{1} \mathrm{H}$ nuclei. For ${ }^{29} \mathrm{Si} \mathrm{NMR}, 10 \mathrm{mg}$ of relaxation agent $\mathrm{Cr}(\mathrm{acac})_{3}$ was added. The Gel Permeation Chromatography (GPC) measurements of polysiloxanes were performed on the PL-50 with a flow rate of $1.0 \mathrm{~mL} / \mathrm{min}$ (THF) at $40{ }^{\circ} \mathrm{C}$. The Differential Scanning Calorimetry (DSC) measurement was conducted on a METTLER DSC1 under a nitrogen atmosphere flow with a heating rate of $10 \mathrm{~K} / \mathrm{min}$. Dynamic Mechanical Analysis (DMA) was carried out on a NETZSCH Dynamic Mechanical Analyzer 242 in shear mode. The testing temperature ranged from -150 to $150{ }^{\circ} \mathrm{C}$, with a heating rate of $3 \mathrm{~K} / \mathrm{min}$ and a frequency of $1 \mathrm{~Hz}$. The elastic modulus was measured at a strain of approximately $0.1 \%$. Emission spectra were recorded on a Perkin-Elmer LS-3 spectrofluorometer. The morphology of polysiloxanes was studied by laser scanning confocal microscopy (LSCM, Leica TCS SP8). For confocal microscopy studies, three polysiloxanes were dissolved in THF and heated at $80^{\circ} \mathrm{C}$ for $8 \mathrm{~h}$ in a vacuum oven.

\subsection{Simulation Methodology}

In light of the unusually pronounced flexibility of polysiloxanes, a more realistic description of siloxane chains is necessary, which means the relaxation of all atoms, rather than a fixed geometry. In this paper, a full-atom MD simulation was carried out using the Materials Studio software (Accelrys, San Diego, CA, USA) with COMPASS (Condensed-phase Optimized Molecular Potentials for Atomistic Simulation Studies) force field. Each system contained three polysiloxane chains with 100 monomers in the construction of amorphous cells of PDMS, PDMS-co-PMPS, and PDMS-co-PDPS (Figure A4). Periodic boundary conditions were applied in the systems to remove the surface effects and obtain the macroscopic properties. The number of $\mathrm{MePhSiO}$ and $\mathrm{Ph}_{2} \mathrm{SiO}$ units was in accordance with the polymerization of PDMS- $-0-P M P S$ and PDMS- $c o-P D P S$. Note that the number of methylvinyl units (MeViSiO) was negligible in all samples.

To eliminate the unfavorable contacts, 20 initial cells of each system were subjected to 50,000 steps of energy minimization by the Smart method with a convergence threshold of $1 \times 10^{-4}\left(\mathrm{kcal} \mathrm{mol}^{-1} \AA^{-1}\right)$. 
Then, cells were annealed at $0.1 \mathrm{MPa}$ from 300 to $500 \mathrm{~K}$ for $2 \mathrm{~ns}$. Subsequently, $5 \mathrm{~ns}$ of NPT (constant number of particles, pressure, and temperature) simulation was performed at $500 \mathrm{~K}$ to further relax the structures. In order to accurately investigate the conformational evolution during the cooling process, the temperature was lowered from 500 to $20 \mathrm{~K}$ in steps of $20 \mathrm{~K}$, and 500 ps of NVT (constant number of particles, volume, and temperature) and 500 ps of NPT were conducted at each temperature. The last structure at each temperature was used for the initial structure of the next temperature. The van der Waals interactions were calculated with the cutoff set at $1.25 \mathrm{~nm}$ and Ewald summation for electrostatic interactions with an accuracy of $1.0 \times 10^{-3}(\mathrm{kcal} / \mathrm{mol})$. In addition, Newton's equation of motion was integrated through the Verlet algorithm at a time step of $1 \mathrm{fs}$. The calculated densities of three polysiloxanes at $300 \mathrm{~K}$ showed good agreement with the experimental results $\left(\left|\rho_{\mathrm{MD}}-\rho_{\text {Exp }}\right|<0.1\right)$, as depicted in Table 2, which means that the simulated models were reliable and feasible for the further investigations.

Table 2. MD simulation and experimental density of polysiloxanes

\begin{tabular}{ccc}
\hline Polymers & Experimental Density $\left(\mathrm{g} / \mathrm{cm}^{-3}\right)$ & Simulated Density $\left(\mathrm{g} / \mathrm{cm}^{-3}\right)$ \\
\hline PDMS & 0.97 & 0.99 \\
PDMS-co-PMPS & 1.06 & 1.10 \\
PDMS-co-PDPS & 1.10 & 1.16 \\
\hline
\end{tabular}

\section{Results and Discussion}

\subsection{Structural Characterization and Sequence Analysis}

The contents of different siloxane units in three samples were obtained from the relative intensities of ${ }^{1} \mathrm{H}$ NMR from phenyl (7.2-7.8 ppm), vinyl (5.6-6.1 ppm), and methyl (-0.1-0.5 ppm) substituents, as tabulated in Table 3. The multiple signals of $\mathrm{Si}-\mathrm{CH}_{3}$ in PDMS-co-PMPS and PDMS-co-PDPS indicated various chemical environments due to the effect of $\mathrm{Si}-\mathrm{C}_{6} \mathrm{H}_{5}$ (Figure A3), but it was impossible to assign each split peak to the corresponding methyl.

Table 3. The results of ${ }^{1} \mathrm{H}$ NMR.

\begin{tabular}{ccccc}
\hline Sample & $\mathbf{M e}_{\mathbf{2}} \mathbf{S i O}(\mathbf{m o l} \%)$ & $\mathbf{M e P h S i O}(\mathbf{m o l} \%)$ & $\mathbf{P h}_{\mathbf{2}} \mathbf{S i O}(\mathbf{m o l} \%)$ & $\mathbf{M e V i S i O}(\mathbf{m o l} \%)$ \\
\hline PDMS & 99.80 & - & - & 0.20 \\
PDMS-co-PMPS & 68.02 & 31.57 & - & 0.41 \\
PDMS-co-PDPS & 68.47 & - & 30.63 & 0.90 \\
\hline
\end{tabular}

Fortunately, ${ }^{29}$ Si NMR spectroscopy is well established as an effective method to determine the microstructures of polysiloxanes [28-33]. As shown in Figure 1a, the ${ }^{29} \mathrm{Si}$ NMR spectrum of PDMS displayed only one peak at $21.91 \mathrm{ppm}$, which corresponded to the $\mathrm{Me}_{2} \mathrm{SiO}$ unit (denoted by D), indicating that the sample was a homopolymer. In contrast, the signals of the copolymers could be conveniently divided into two parts. For PDMS-co-PMPS, -20 to $-22 \mathrm{ppm}$ originated from $\mathrm{D}$ groups, and -33 to $-35 \mathrm{ppm}$ from the $\mathrm{MePhSiO}$ unit (denoted by $\mathrm{D}^{\mathrm{Ph}}$ ). Similarly, in the spectrum of PDMS-co-PDPS, -19 to $-22 \mathrm{ppm}$ corresponded to D groups, and -46 to $-49 \mathrm{ppm}$ to the $\mathrm{Ph}_{2} \mathrm{SiO}$ unit (denoted by $\mathrm{D}^{\mathrm{Ph} 2}$ ). The $\mathrm{MeViSiO}$ unit was hardly observed due to the very small quantity present. The chemical shift of silicon was sensitive to neighboring siloxane groups; as a result, each region contained three sets of resonances in copolymers. Six different triad groupings, including three D-centered triads (DDD, D'DD or DDD', D'DD') and three $\mathrm{D}^{\prime}$-centered triads (DD'D, D'D'D or DD'D', D'D' $\mathrm{D}^{\prime}$ ), could be identified in the ${ }^{29} \mathrm{Si}$ NMR spectra of PDMS-co-PMPS and PDMS-co-PDPS, as shown in Figure $1 \mathrm{~b}, \mathrm{c}$ ( $\mathrm{D}^{\prime}$ refer to $\mathrm{D}^{\mathrm{Ph}}$ or $\mathrm{D}^{\mathrm{Ph} 2}$ in PDMS-co-PMPS and PDMS-co-PDPS, respectively). The chemical shifts and intensities are presented in Table 4, showing that increasing number of $\mathrm{D}^{\mathrm{Ph}}$ or $\mathrm{D}^{\mathrm{Ph} 2}$ units in triad groupings led to low-field shifts of ${ }^{29} \mathrm{Si}$ NMR. 
(a)

$$
\overline{\bar{T}}
$$

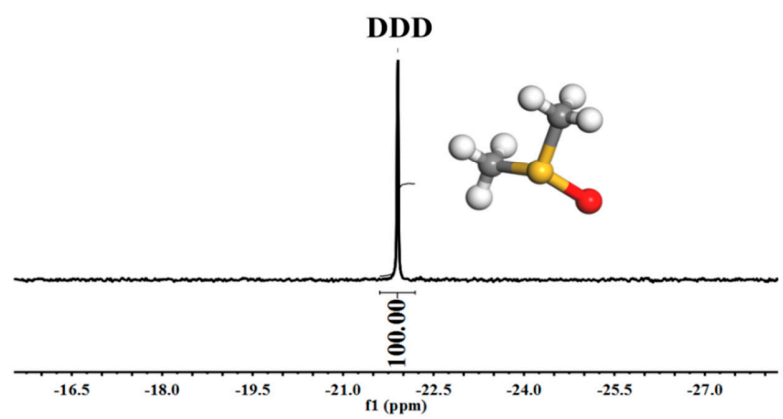

(b)

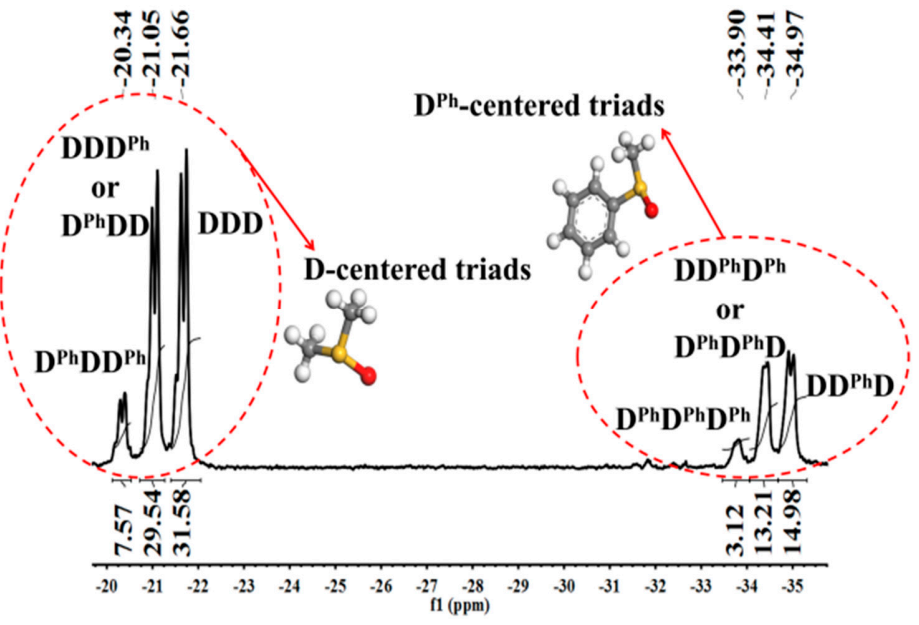

(c)

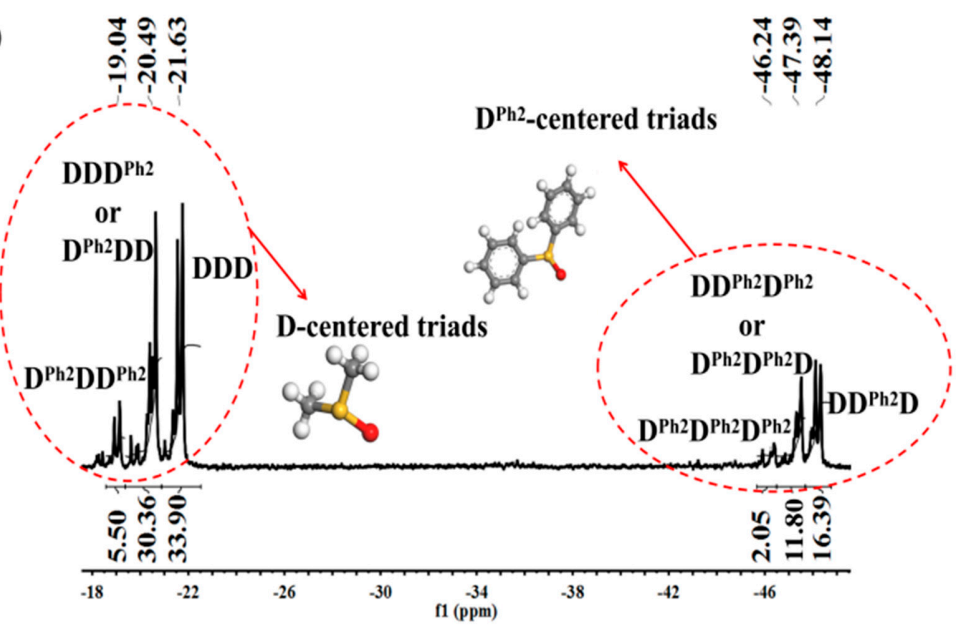

Figure 1. ${ }^{29} \mathrm{Si}$ NMR spectra of (a) PDMS, (b) PDMS-co-PMPS, and (c) PDMS-co-PDPS, in CDCl $\mathrm{C}_{3}$. 
Table 4. ${ }^{29} \mathrm{Si}$ NMR chemical shifts and intensities for polysiloxanes.

\begin{tabular}{|c|c|c|c|c|c|c|}
\hline \multirow{2}{*}{ Triad } & \multicolumn{2}{|c|}{ PDMS } & \multicolumn{2}{|c|}{ PDMS-co-PMPS } & \multicolumn{2}{|c|}{ PDMS-co-PDPS } \\
\hline & $\delta(\mathrm{ppm})$ & Intensity (\%) & $\delta(\mathrm{ppm})$ & Intensity (\%) & $\delta(\mathrm{ppm})$ & Intensity (\%) \\
\hline \multicolumn{7}{|c|}{ D centered } \\
\hline DDD & -21.91 & 100 & -21.66 & 31.58 & -21.63 & 33.90 \\
\hline $\mathrm{DDD}^{\prime}+\mathrm{D}^{\prime} \mathrm{DD}$ & - & - & -21.05 & 29.54 & -20.49 & 30.36 \\
\hline $\mathrm{D}^{\prime} \mathrm{DD}^{\prime}$ & - & - & -20.34 & 7.57 & -19.04 & 5.50 \\
\hline \multicolumn{7}{|c|}{$\mathrm{D}^{\prime}$ centered } \\
\hline $\mathrm{DD}^{\prime} \mathrm{D}$ & - & - & -34.97 & 14.98 & -48.14 & 16.39 \\
\hline $\mathrm{DD}^{\prime} \mathrm{D}^{\prime}+\mathrm{D}^{\prime} \mathrm{D}^{\prime} \mathrm{D}$ & - & - & -34.41 & 13.21 & -47.39 & 11.80 \\
\hline $\mathrm{D}^{\prime} \mathrm{D}^{\prime} \mathrm{D}^{\prime}$ & - & - & -33.90 & 3.12 & -46.24 & 2.05 \\
\hline
\end{tabular}

According to the literature, there was an exclusively isolated phenyl unit along the polymer chain in low phenyl polysiloxanes, which yielded an overwhelmingly dominant signal for the triad sequence of $\mathrm{DD}^{\prime} \mathrm{D}$ and a barely visible signal for $\mathrm{DD}^{\prime} \mathrm{D}^{\prime} / \mathrm{D}^{\prime} \mathrm{D}^{\prime} \mathrm{D}$ or $\mathrm{D}^{\prime} \mathrm{D}^{\prime} \mathrm{D}^{\prime}[5,6]$. In contrast, the contents of $\mathrm{DD}^{\prime} \mathrm{D}^{\prime} / \mathrm{D}^{\prime} \mathrm{D}^{\prime} \mathrm{D}$ and $\mathrm{D}^{\prime} \mathrm{D}^{\prime} \mathrm{D}^{\prime}$ in PDMS-co-PMPS and PDMS-co-PDPS were significantly increased, with relative intensities up to 16.33 and 13.85, respectively. To further calculate the sequence distributions quantitatively, a simple linkage-probability method was adopted which utilized the composition and relative intensities of ${ }^{29} \mathrm{Si}$ NMR signals from the repeat unit triads [34]. The run number $(R)$, referring to the average number of monomer sequences (runs) in 100 repeating units of copolymers, was calculated by the Equation (1) $[35,36]$ :

$$
R=f_{D} \cdot M_{D}=f_{D^{\prime}} \cdot M_{D^{\prime}}
$$

where $M_{\mathrm{D}}$ and $M_{\mathrm{D}^{\prime}}$ refer to the molar percentages of $\mathrm{D}$ and $\mathrm{D}^{\prime}$ as calculated by ${ }^{1} \mathrm{H} N M R . \mathrm{f}_{\mathrm{D}}$ and $\mathrm{f}_{\mathrm{D}^{\prime}}$ correspond to the signal intensity ratio for $\mathrm{D}$ and $\mathrm{D}^{\prime}$ units, as shown in Table 4, which can be calculated by Equations (2) and (3):

$$
\begin{aligned}
f_{D} & =2\left[F_{D^{\prime} D D^{\prime}} /\left(F_{D^{\prime} D D^{\prime}}+F_{D^{\prime} D D}+F_{D D D}\right)\right]^{0.5} \\
f_{D^{\prime}} & =2\left[F_{D D^{\prime} D} /\left(F_{D^{\prime} D^{\prime} D^{\prime}}+F_{D D^{\prime} D^{\prime}}+F_{D D^{\prime} D}\right)\right]^{0.5}
\end{aligned}
$$

where $F_{\mathrm{D}^{\prime} \mathrm{DD}^{\prime},} F_{\mathrm{D}^{\prime} \mathrm{DD}}, F_{\mathrm{DDD}}, F_{\mathrm{DD}^{\prime} \mathrm{D}}, F_{\mathrm{D}^{\prime} \mathrm{D}^{\prime} \mathrm{D}^{\prime}}$, and $F_{\mathrm{DD}^{\prime} \mathrm{D}^{\prime}}$ are the integral areas of the indicated $\mathrm{D}$ and $\mathrm{D}^{\prime}$-centered triads, respectively. The run number for random polymers is given by Equation (4), and the calculated results are listed in Table 5.

$$
R_{\text {random }}=\frac{M_{D} \times M_{D^{\prime}}}{50}
$$

Table 5. Microstructural analysis of PDMS-co-PMPS and PDMS-co-PDPS based on ${ }^{29}$ Si NMR.

\begin{tabular}{cccccc}
\hline Polymer & $\mathbf{f}_{\mathbf{D}}$ & $\mathbf{f}_{\mathbf{D}^{\prime}}$ & $\mathbf{R}_{\mathbf{D}}$ & $\mathbf{R}_{\mathbf{D}^{\prime}}$ & $\mathbf{R}_{\text {random }}$ \\
\hline PDMS-co-PMPS & 0.664 & 1.383 & 45.16 & 43.67 & 42.95 \\
PDMS-co-PDPS & 0.562 & 1.472 & 38.45 & 45.10 & 41.94 \\
\hline
\end{tabular}

Theoretically, if $R_{\exp }<R_{\text {random, }}$ the microstructure of the copolymer is composed of sequences containing blocks of monomer units; if $R_{\exp }>R_{\text {random, }}$ the microstructure consists predominantly of alternating monomer units; and if $R_{\exp }=R_{\text {random, }}$ the microstructure is random (statistical). As shown in Table $5, R_{\mathrm{D}}$ and $R_{\mathrm{D}^{\prime}}$ are very close to the value $R_{\text {random }}$ calculated for complete random distribution. As a consequence, the microstructures are concluded to be random in PDMS-co-PMPS and PDMS-co-PDPS. It is worth noting that $R_{\mathrm{D}}$ significantly exceeds $R_{\text {random }}$ in low phenyl polysiloxanes, which strongly suggests the alternation of single phenyl units and extended dimethyl units [6], i.e., the large number of phenyl units not only shortens the sequence length of dimethyl units, but also increases the proportion 
of consecutive phenyl units. Therefore, the sequence distributions become much more complicated compared to those in low phenyl polysiloxanes. Special monomer sequences have a dramatic impact on the conformations of copolymers, and would account for the unique performance of high-phenyl polysiloxanes, as we will illustrate in detail by means of MD simulation in the subsequent sections.

\subsection{Configuration and Conformation of Polysiloxane Chains}

MD simulation provides a profoundly useful method by which to study condensed phase properties of polymers at the molecular level. In this section, the configurations were investigated based on the sequence distribution, and the conformational evolutions were analyzed by the MD trajectories during the cooling process.

Figure 2 shows the bond angle distributions of polysiloxanes at different temperatures, and mainly displays two features. Firstly, there is a significant difference between the two consecutive bond angles: the $\mathrm{Si}-\mathrm{O}-\mathrm{Si}$ angle is very flexible with a bare $\mathrm{O}$ atom, measuring between $130^{\circ}-180^{\circ}$, which endows the chain with an unusual flexibility; the $\mathrm{O}-\mathrm{Si}-\mathrm{O}$ angle, on the other hand, is much more rigid and measured between $105^{\circ}-120^{\circ}$, depending on the nature of the two substituents on the Si atom. Secondly, the distribution widths gradually narrow around the central theoretical values $(\mathrm{Si}-\mathrm{O}-\mathrm{Si}$ angle is $143^{\circ}$ and $\mathrm{O}-\mathrm{Si}-\mathrm{O}$ angle is $109.5^{\circ}$ ) during the cooling procedure, indicating a decrease in the number of stable conformations. Moreover, compared with PDMS, it has been found that the more phenyl groups the polysiloxane has, the wider angle distribution curves become by expanding to the right (larger angle direction), especially in the $\mathrm{O}-\mathrm{Si}-\mathrm{O}$ angle. The large and highly-flexible bond angle is supplemented by the relatively long $\mathrm{Si}-\mathrm{O}(1.64 \AA)$ and $\mathrm{Si}-\mathrm{C}(1.88 \AA)$ bonds, which increases the spatial separation of the neighboring side groups and reduces the steric interferences. In the carbon chains of vinyl polymers, the spatial repulsions are the dominant interactions between side groups because of atom crowding; in contrast, the interactions are attractive, particularly when two phenyl rings are involved in polysiloxanes.

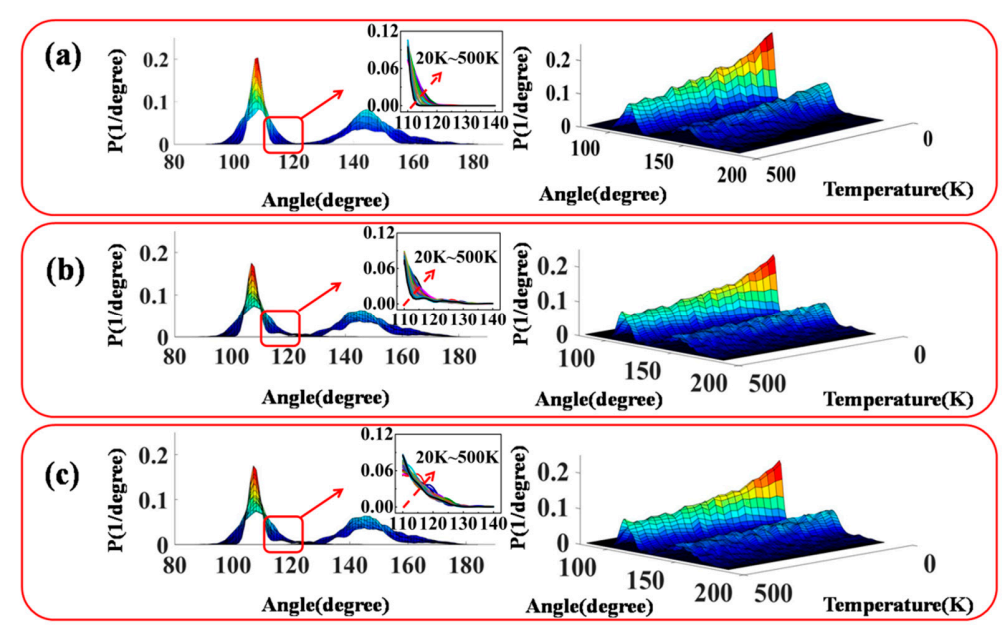

Figure 2. Bond angle distributions of (a) PDMS, (b) PDMS-co-PMPS, and (c) PDMS-co-PDPS. The left plots are the front views of the tri-dimensional plots, and the right ones show the distribution at different temperatures.

The radial distribution function $\mathrm{g}(\mathrm{r})$, as a useful tool for studying the conformational properties of polymer systems, provides an effective method for evaluating interactions including the bonding or non-bonding atoms [37]. It is given by Equation (5):

$$
g_{A B}(r)=\frac{1}{\rho_{A B} 4 \pi r^{2}} \frac{\sum_{t=1}^{K} \sum_{j=1}^{N_{A B}} \Delta N_{A B}(r \rightarrow r+\delta \mathbf{r})}{N_{A B} \times K}
$$


where $\rho_{\mathrm{AB}}$ is the density of the system, $N_{\mathrm{AB}}$ represents the total number of atoms of $\mathrm{A}$ and $\mathrm{B}, K$ is the number of time steps, $\delta \mathrm{r}$ is the distance interval, and $\Delta N_{\mathrm{AB}}$ is the number of $\mathrm{B}$ (or $\mathrm{A}$ ) atoms between $\mathrm{r}$ to $\mathrm{r}+\delta \mathrm{r}$ around an $\mathrm{A}$ (or B) atom [38].

In order to quantitatively investigate the effects of different sequence distributions on intraand inter- molecular interactions, the $\mathrm{g}(\mathrm{r})$ of $\mathrm{Si}-\mathrm{O}$ was calculated. According to the results of ${ }^{29} \mathrm{Si}$ NMR (Table 4), four dominant triad sequences (DDD, $\mathrm{DDD}^{\prime} / \mathrm{D}^{\prime} \mathrm{DD}, \mathrm{DD} \mathrm{D}^{\prime}$, and $\mathrm{DD}^{\prime} \mathrm{D}^{\prime} / \mathrm{D}^{\prime} \mathrm{D} \mathrm{D}^{\prime} \mathrm{D}$ ) in PDMS-co-PMPS and PDMS-co-PDPS were studied at 300K, compared with PDMS (only the DDD sequence). As seen from the results in Figure 3, the intra $g(r)$ shows a rise at $1.64 \AA$, owing to the bond length of $\mathrm{Si}-\mathrm{O}$. The appearance of high and sharp peaks from 2-5 $\AA$ in PDMS-co-PMPS and PDMS-Co-PDPS, indicating a strong van der Waals interactions, arises from the interactions of phenyl-phenyl and methyl-phenyl [24,39]; in contrast, there are only a few weak peaks in PDMS due to the interaction of methyl-methyl. On the other hand, the inter $\mathrm{g}(\mathrm{r})$ shows that the distances between different chains is stable from ca. $8 \AA$ in PDMS and PDMS-co-PMPS, while in the PDMS-co-PDPS, various phenyl sequences undergo continuous interaction from ca. $4 \AA$, demonstrating stronger intermolecular interactions. These results can be rationalized by the following structural factors: the side groups of the methyl stay outward and shield the main chain in PDMS, leading to both weak interactions between the side groups and very little interpenetration of the chains. In PDMS-co-PMPS and PDMS-co-PDPS, the attraction between phenyl groups strengthens the intra- and inter- molecular interactions and destroys the regular structure in PDMS, especially consecutive phenyl units.

(a)

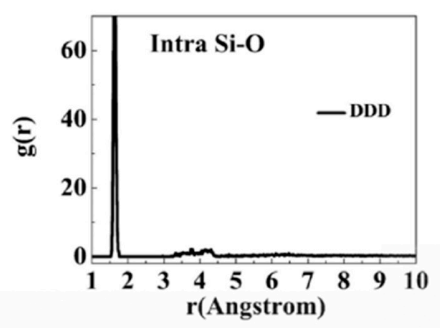

(b)

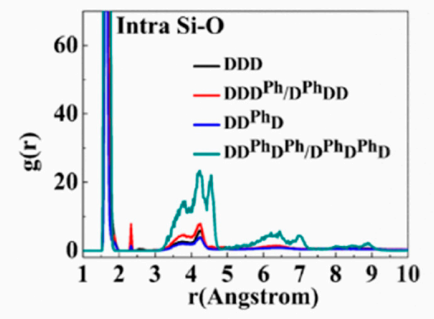

(c)

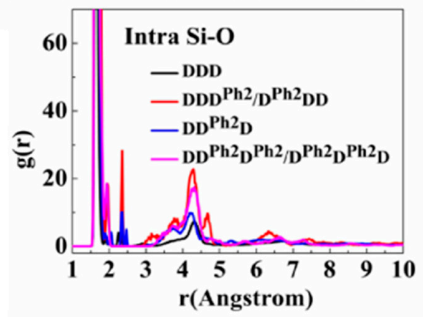

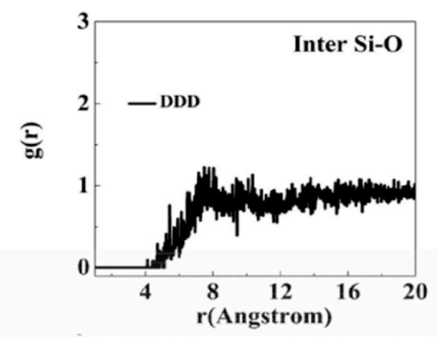
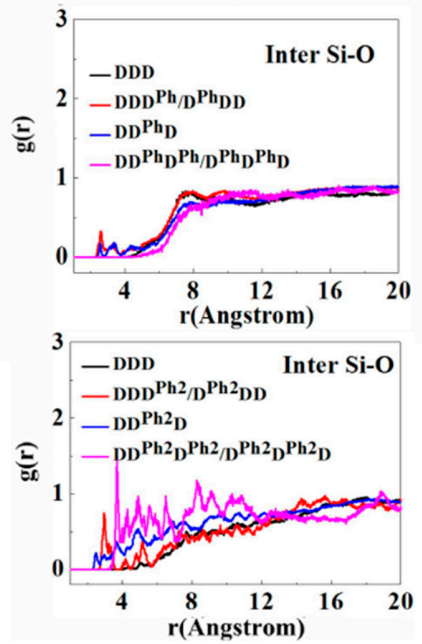

Figure 3. Radial distribution functions of the intra- and inter- molecular Si-O of (a) PDMS, (b) PDMS-co-PMPS, and (c) PDMS-Co-PDPS at $300 \mathrm{~K}$.

Furthermore, molecular chains are restricted from performing coupling rotation due to the attraction of phenyl groups, which has a significant influence on the conformations. The torsion distributions along the backbone represent the conformational ordering of chains [40], as shown in Figure 4. According to the distribution, three kinds of microconformation, i.e., trans state ( $\mathrm{T}$, at \pm 180 degree), right gauche $\left(\mathrm{G}^{-}\right.$, at 60 degree), and left gauche $\left(\mathrm{G}^{+}\right.$, at -60 degree), are defined at the left tri-dimensional plots. The middle plots show the distribution at different temperatures. The ball and stick models on the right are representative configurations of whole molecules obtained from the 
equilibrated MD simulation, and the green parts are phenyl groups. With a decrease of temperature, the increased peak heights and narrowed torsion distributions indicate the typical behavior for chain fluids. In PDMS, the rotational state is not sharply defined, and all values of the torsion angle have a significant probability, indicating the extraordinary flexibility of the molecular chains. Comparatively, the conformational surfaces of PDMS-co-PMPS and PDMS-co-PDPS become obviously deeper, and the higher ratio of trans-to-gauche conformations demonstrates an increase in rigidity. The helix molecular chain (PDMS) gradually evolves into a short, rod-shaped structure (PDMS-co-PDPS), which further confirms the decrease of flexibility and leads to a higher glass transition temperature $\left(T_{\mathrm{g}}\right)$. This conclusion is consistent with the experimental observation (DSC, Table 1), and is in line with the theory of chain flexibility [2].

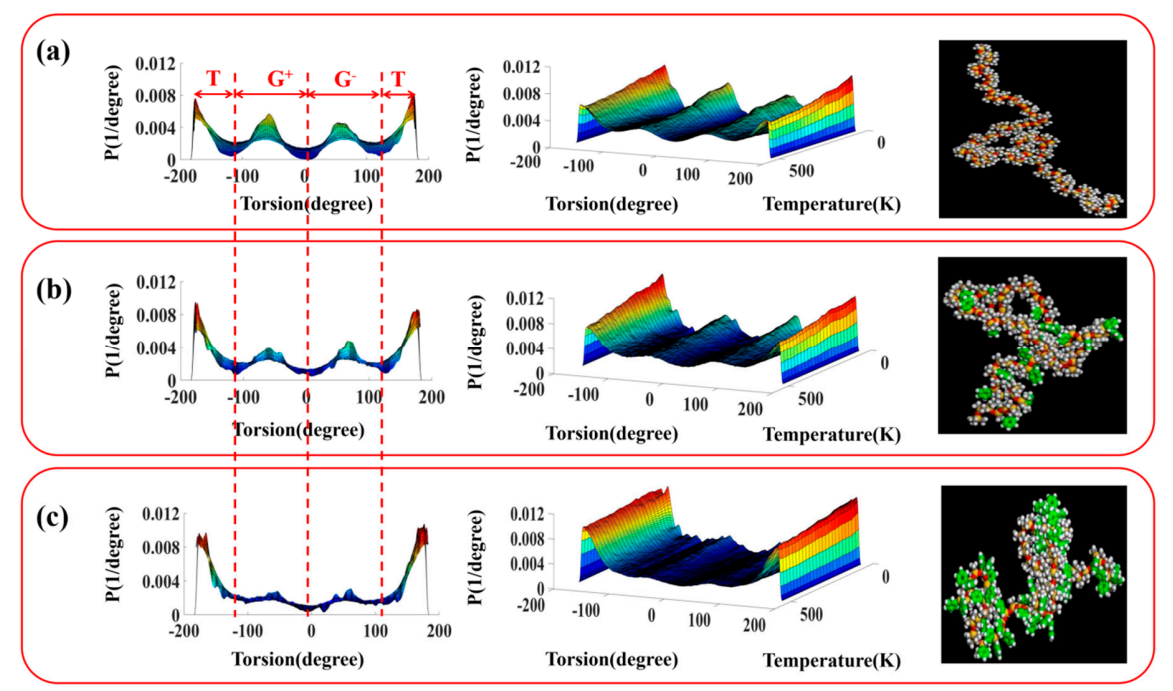

Figure 4. Torsion distributions of (a) PDMS, (b) PDMS-co-PMPS, and (c) PDMS-co-PDPS at different temperatures.

\subsection{Thermodynamics Properties}

The special sequence structures and conformations determine the macroscopic properties of high-phenyl polysiloxanes through molecular motion. In order to estimate the random mobility of molecular chains in systems, the mean-squared displacements (MSD) at various temperatures were obtained from the initial 200 ps of each NPT ensemble, which is expressed as follows:

$$
M S D=\frac{1}{3 N} \sum_{i=0}^{N-1}\left\langle\left|\vec{R}_{i}(t)-\vec{R}_{i}(0)\right|^{2}\right\rangle
$$

In Equation (6), $\vec{R}_{i}(0)$ and $\vec{R}_{i}(t)$ denotes the initial and current position of $i$ atom, $N$ is the number of atoms, and the brackets $<>$ denote the average over all atoms and times [41].

As shown in Figure 5, the motion of polysiloxane chains reduces consistently during the cooling process. The mobility of PDMS-co-PMPS and PDMS-co-PDPS decrease markedly compared with PDMS, owing to stronger interactions and higher rigidity, as illustrated by the results of $\mathrm{g}(\mathrm{r})$ and torsion distributions. Furthermore, it is acknowledged that the glass transition of polymers is mainly determined by the change in the mobility of molecules with temperature; thus, the MSD can provide a rational estimation of glass transition temperature $\left(T_{\mathrm{g}}\right)$ [42-44]. When polysiloxanes experience a glassy-to-rubbery phase transition, the torsional motions and local segmental movements enable the disentanglement of chains, leading to an abrupt change at the low and high temperature ranges in the MSD-temperature curves. Figure 6 shows that $T_{\mathrm{g}}$ can be obtained by the intersection of two linear lines that are fitted to the MSD-temperature data between the two temperature regions. The calculated $T_{\mathrm{g}} \mathrm{s}$ 
of PDMS, PDMS-co-PMPS, and PDMS-co-PDPS are 152, 182, and $220 \mathrm{~K}$, respectively, which is in good agreement with the experimental results of DSC $(149,183$, and $214 \mathrm{~K}$, respectively). The results validate the accuracy of the simulation; the ability to predict $T_{\mathrm{g}}$ according to the microstructure will be of great value in the selection and design of new materials. In addition, $T_{\mathrm{g}}$ is a key indicator for evaluating the performance of polymers in practical applications, especially in terms of damping materials.
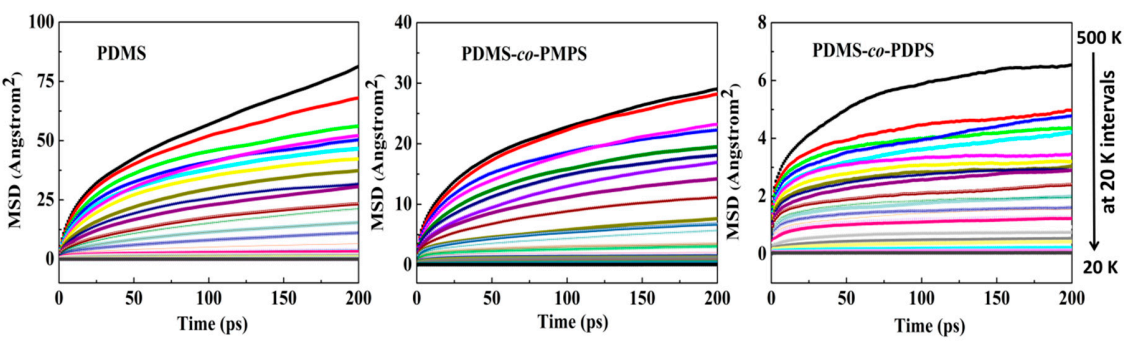

Figure 5. MSD curves as a function of time at different temperatures.
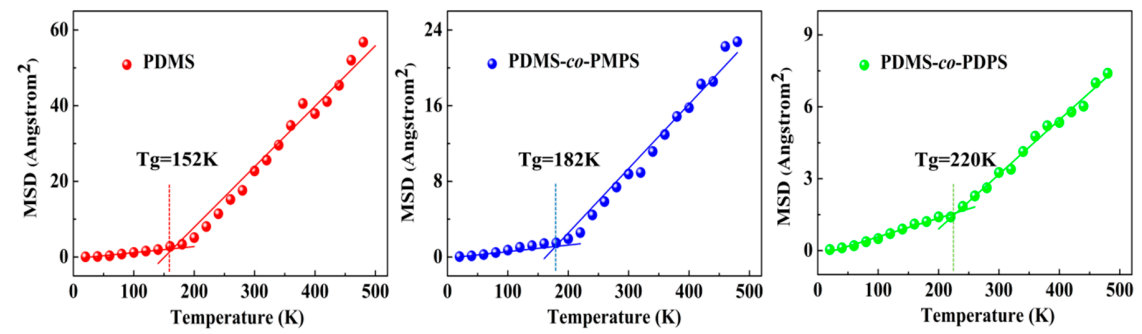

Figure 6. MSD curves as a function of temperature obtained at $100 \mathrm{ps}$.

In general, the frozen segments could dissipate a large amount of energy through coordinated molecular movement during the glass-rubber transition. The ability of dissipation is estimated by the loss tangent $(\tan \delta)$, which is defined as the ratio of loss modulus to storage modulus $[45,46]$. The dynamic mechanical properties of three polysiloxanes were evaluated by the dynamic mechanical analysis (DMA); the results are presented in Figure 7. In PDMS, the max tan $\delta$ is very low (about 0.1) and the shoulder peaks from -90 to $-50{ }^{\circ} \mathrm{C}$ stem from the cold crystallization and crystal melting, which limit its applications at low temperature. In contrast, the max $\tan \delta$ could reach about 1.6 in PDMS-co-PMPS and PDMS-co-PDPS, and the valid damping $(\tan \delta>0.3)$ temperature ranges move to high temperature. The phenomenon is due to the strong interactions and steric hindrance of phenyl groups, which significantly increase the internal friction. Interestingly, PDMS-co-PDPS has the most phenyl groups, but its max $\tan \delta$ is even slightly lower than PDMS-co-PMPS. This is mainly because the restricted segmental movements limit the dissipation of energy. Consequently, we conclude that the optimal damping properties depend on the balance between interaction strength and motion capability.

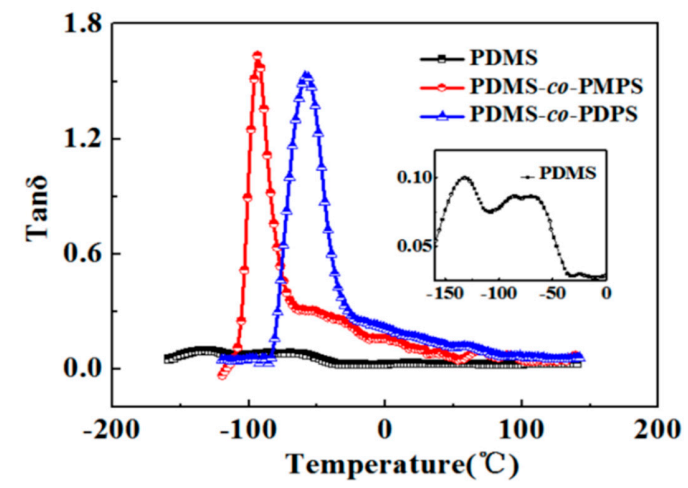

Figure 7. Dynamic mechanical analysis (DMA) results of polysiloxanes at $1 \mathrm{~Hz}$. 
Additionally, for DMA as a conventional method for detecting changes in the glass transition, $T_{\mathrm{g}}$ is generally reported as the location of the peak in the $\tan \delta$. As shown in Figure 7, the $T_{\mathrm{gS}}$ of PDMS, PDMS-co-PMPS, and PDMS-co-PDPS are $-125^{\circ} \mathrm{C}(148 \mathrm{~K}),-92{ }^{\circ} \mathrm{C}(181 \mathrm{~K})$, and $-60^{\circ} \mathrm{C}(213 \mathrm{~K})$, respectively. The observations are consistent with the calculated results of $\operatorname{MSD}(152,182$, and $220 \mathrm{~K}$, respectively), and once again verify the reliability of the simulations.

\subsection{Photophysical Properties}

The multitude of spatial conformations, generated by various monomer sequences, also endows phenyl polysiloxanes with intrinsic photophysical properties. Owing to the attractions between phenyl groups, the stable conformations of the triad sequence of $\mathrm{DD}^{\prime} \mathrm{D}^{\prime}$ or $\mathrm{D}^{\prime} \mathrm{D}^{\prime} \mathrm{D}$ (Table 4) occur when a pair of phenyl rings are coupled face-to-face in parallel, becoming an excimer-forming site (EFS); for triad sequence of $\mathrm{D}^{\prime} \mathrm{D}^{\prime} \mathrm{D}^{\prime}$ (Table 4), the stable conformations also occur when two phenyl rings are coupled in parallel, but not necessarily in the nearest-neighbor [23]. Based on the above analysis, we predicted that PDMS-co-PMPS and PDMS-co-PDPS would exhibit obvious fluorescence performance, and experimental testings were performed to evaluate the photophysical behavior.

Figure 8 reports the fluorescence emission spectra of PDMS, PDMS-co-PMPS, and PDMS-co-PDPS in solid state with an excitation wavelength $\lambda_{\mathrm{ex}}=290 \mathrm{~nm}$. The emission spectra of PDMS-co-PMPS and PDMS-co-PDPS displayed a strong excimer component about $350 \mathrm{~nm}$, compared to $325 \mathrm{~nm}$ in dilute solutions [9,14]; a significant red shift occurred, which was ascribed to the enhanced intra- and intermolecular interactions. PDMS had no obvious emission at all wavelengths. PDMS-co-PDPS showed a stronger excimer emission with respect to PDMS-co-PMPS, which was due mainly to two molecular factors: firstly, the more phenyl groups and stronger interactions led to a higher concentration of EFS; secondly, the lower chain flexibility and motion capability enabled a more stable EFS state [12]. The observations agreed well with our predictions.

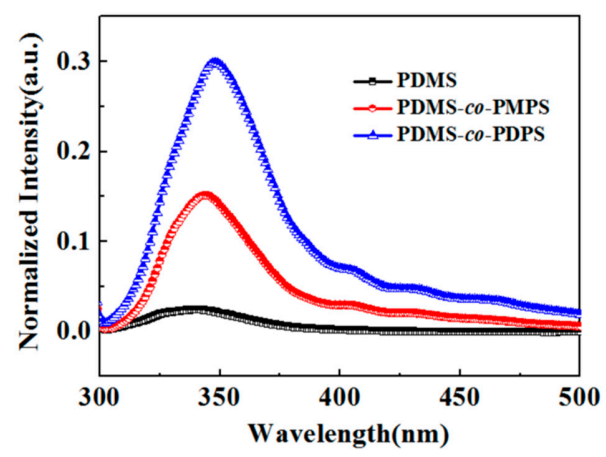

Figure 8. Fluorescence emission spectra of PDMS, PDMS-co-PMPS and PDMS-co-PDPS in solid state, collected under excitation at $290 \mathrm{~nm}$ at room temperature.

Encouraged by the above results, we further investigated the phase morphology of PDMS, PDMS-co-PMPS, and PDMS-co-PDPS in solid state using a laser scanning confocal microscopy (LSCM) [47]; the results are presented in Figure 9. Since PDMS has no fluorescence, it is not visible in the fluorescent image. In contrast, the fluorescent patterns of PDMS-co-PMPS and PDMS-co-PDPS display intense blue fluorescence. The intrinsic fluorescence property of high-phenyl polysiloxanes enabled the direct observation and differentiation of microphase separations in blend systems by fluorescence-based techniques, and without extra dyeing. This will provide a new strategy to investigate the underlying relationships between the morphology and performance of materials, which is significant from both an academic and a practical point of view [48]. 

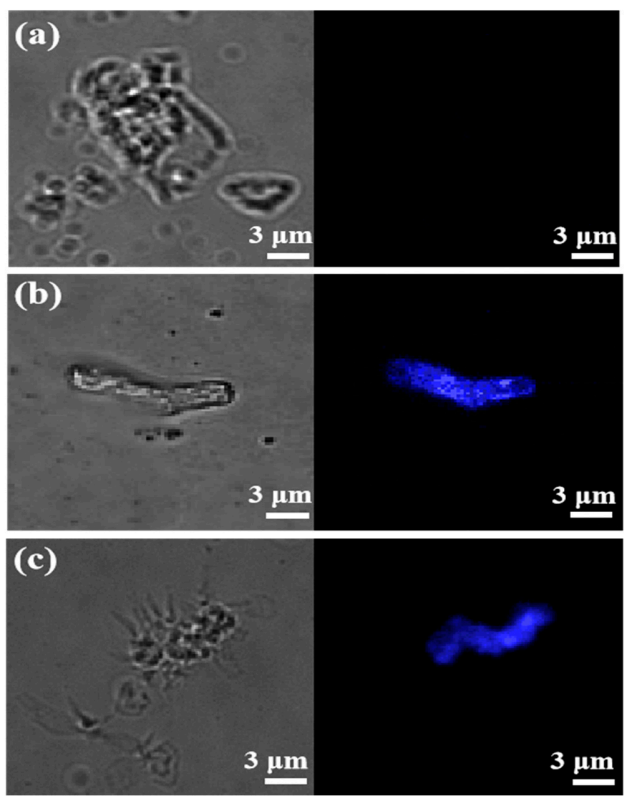

Figure 9. LSCM optical of polysiloxanes: (a) PDMS, (b) PDMS-co-PMPS, and (c) PDMS-co-PDPS in solid state under excitation at $405 \mathrm{~nm}$ at room temperature; left bright-field and right fluorescent.

\section{Conclusions}

The sequence distributions and microstructures of PDMS, PDMS-co-PMPS, and PDMS-co-PDPS were systematically investigated by molecular dynamics simulations combining experimental methods. Monomer sequences were quantitatively calculated by the ${ }^{29} \mathrm{Si} \mathrm{NMR}$, which indicated the large number of phenyl units not only shortened the length of dimethyl units, but also significantly increased the proportion of consecutive phenyl units. The results of the simulation demonstrated that the attraction between adjacent phenyl groups effectively strengthened the intra- and inter- molecular interactions, which led to a decrease of chain flexibility and motion capability. The dynamic mechanical properties and photophysical behavior correlated with the conformational evolutions, and the simulation results were consistent with the experimental observations.

Author Contributions: Conceptualization, L.Z. and C.Z.; Data curation, L.Z. and X.C.; Funding acquisition, C.Z.; Investigation, L.Z. and W.S.; Software, L.Z.; Writing—original draft, L.Z.; Writing—review \& editing, J.Z.

Funding: This study was supported financially by the National Natural Science Foundation of China (21702214).

Conflicts of Interest: The authors declare no conflict of interest.

\section{Appendix A.}

\section{Appendix A.1. DSC of Polysiloxanes}

The DSC scan of the PDMS shows a glass transition $T_{\mathrm{g}}$ at $-123^{\circ} \mathrm{C}$, a crystallization exotherm $\left(T_{\mathrm{C}}\right)$ at $-89^{\circ} \mathrm{C}$, and a melting endotherm $\left(T_{\mathrm{m}}\right)$ about $-45^{\circ} \mathrm{C}$. The DSC results of copolymers exhibit only one second-order phase transition and the measured $T_{\mathrm{g}}$ values of PDMS-co-PMPS and PDMS-co-PDPS are -90 and $-59^{\circ} \mathrm{C}$.

In addition, two endothermic peaks at -46 and $-39^{\circ} \mathrm{C}$ are observed in the PDMS and the total area for both peaks corresponded to a $\Delta H=32.63 \mathrm{~J} / \mathrm{g}$. Comparison to the heat of fusion of completely crystalline PDMS, $\Delta H_{\mathrm{m}}=37.4 \mathrm{~J} / \mathrm{g}$, the cooled PDMS sample is $87 \%$ crystalline. 


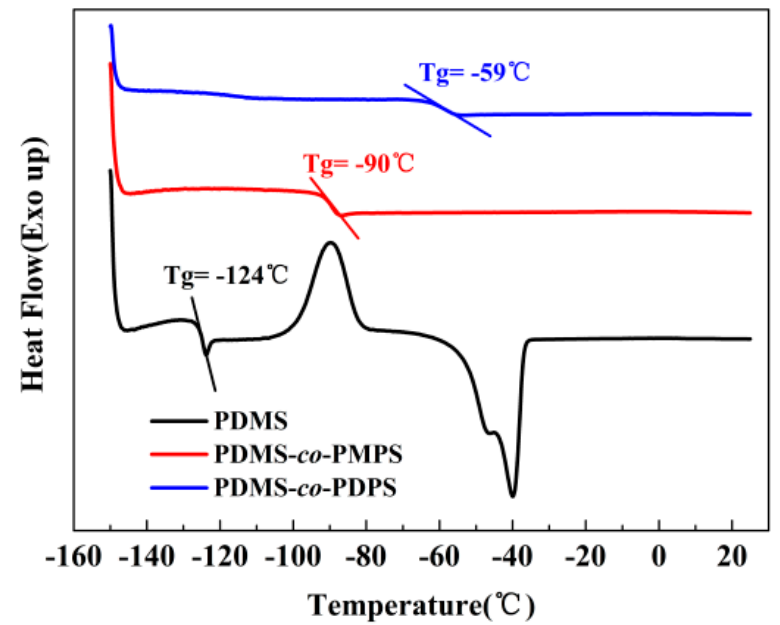

Figure A1. The DSC results of PDMS, PDMS-co-PMPS, and PDMS-co-PDPS ( $T_{\mathrm{g}}$ corresponds to the temperature at which $50 \%$ of the transition is complete).

Appendix A.2. GPC of Polysiloxanes

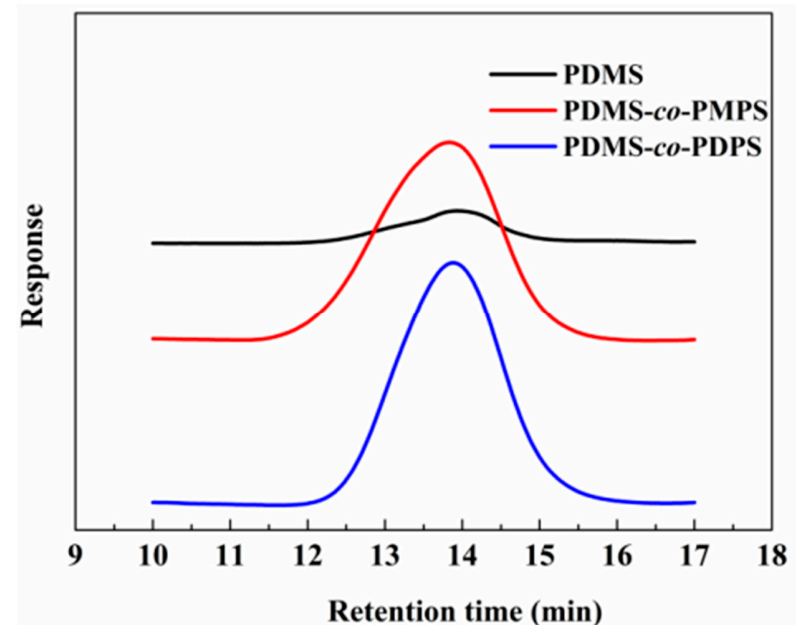

Figure A2. The GPC results of PDMS, PDMS-co-PMPS, and PDMS-co-PDPS, in THF.

Appendix A.3. 1H NMR of Polysiloxanes

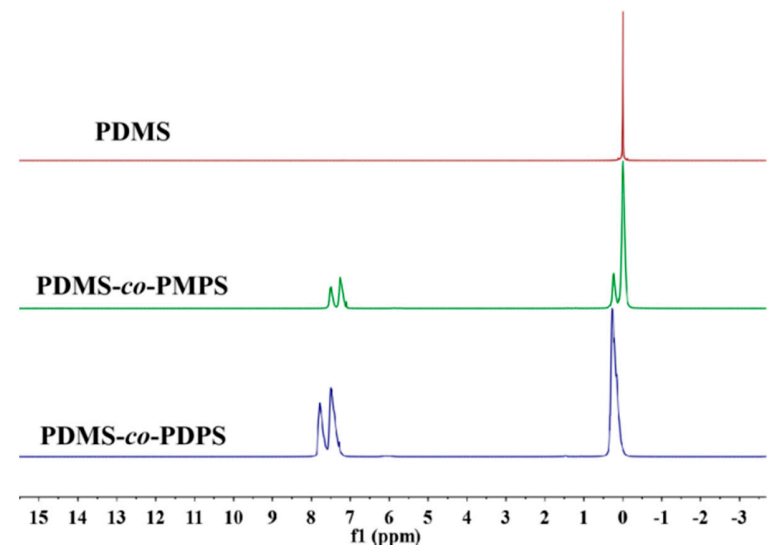

Figure A3. The ${ }^{1} \mathrm{H}$ NMR results of PDMS, PDMS-co-PMPS, and PDMS-co-PDPS, in $\mathrm{CDCl}_{3}$. 
(a)

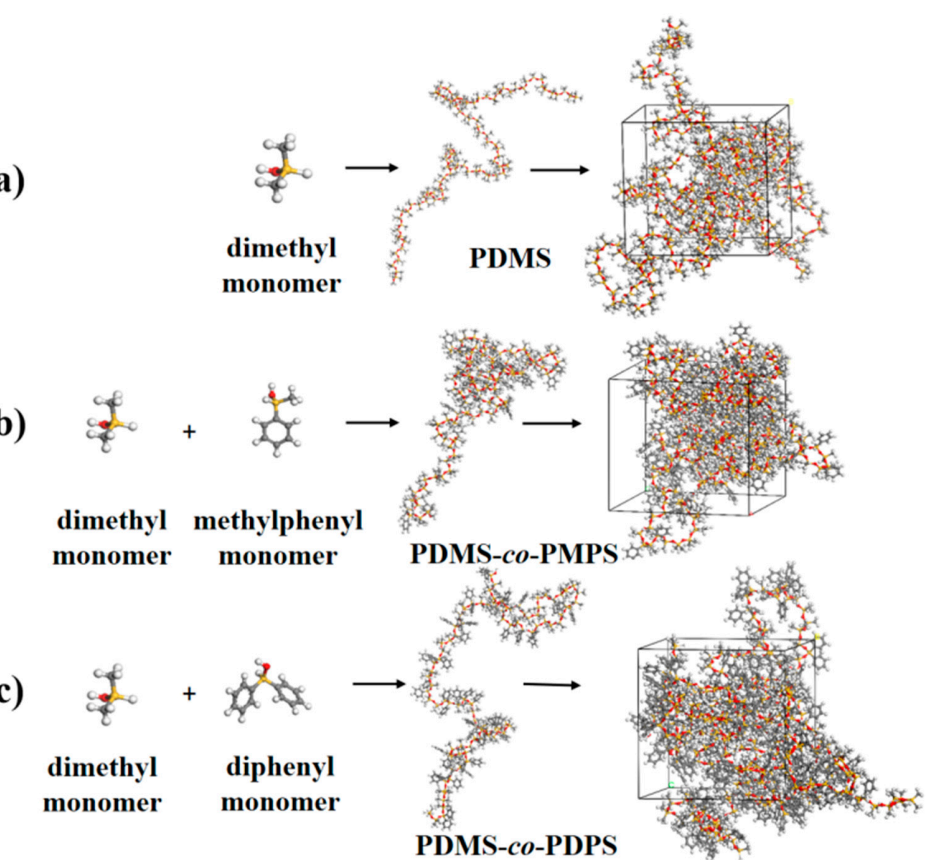

Figure A4. Process of construction of the amorphous cell (a) PDMS (b) PDMS-co-PMPS (c) PDMS-co-PDPS (yellow sphere is $\mathrm{Si}$, red sphere is $\mathrm{O}$, grey sphere is $\mathrm{C}$, white sphere is $\mathrm{O}$ ).

\section{References}

1. Ren, Z.J.; Yan, S. Polysiloxanes for optoelectronic applications. Prog. Mater. Sci. 2016, 83, 383-416. [CrossRef]

2. Yilgör, E.; Yilgör, I. Silicone containing copolymers: Synthesis, properties and applications. Prog. Polym. Sci. 2014, 39, 1165-1195. [CrossRef]

3. Shi, J.F.; Zhao, N.; Xia, S.; Liu, S.F.; Li, Z.B. Phosphazene superbase catalyzed ring-opening polymerization of cyclotetrasiloxane toward copolysiloxanes with high diphenyl siloxane content. Polym. Chem. 2019, 10, 2126-2133. [CrossRef]

4. Qu, L.L.; Huang, G.S.; Wang, Q.; Xie, Z.J. Effect of diphenylsiloxane unit content on aggregation structure of poly(dimethylsiloxane-co-diphenylsiloxane). J. Polym. Sci. Polym. Phys. 2008, 46, 72-79. [CrossRef]

5. Zlatanic, A.; Radojcic, D.; Wan, X.M.; Messman, J.M.; Dvornic, P.R. Suppression of crystallization in polydimethylsiloxanes and chain branching in their phenyl-containing copolymers. Macromolecules 2017, 50, 3532-3543. [CrossRef]

6. Zlatanic, A.; Radojcic, D.; Wan, X.M.; Messman, J.M.; Bowen, D.E.; Dvornic, P.R. Dimethyl-methylphenyl copolysiloxanes by dimethylsilanolate-initiated ring opening polymerization. Evidence for linearity of the resulting polymer structures. J. Polym. Sci. Polym. Chem. 2019, 57, 1122-1129. [CrossRef]

7. Chou, C.; Yang, M.H. Structural effects on the thermal properties of PDPS/PDM copolymers. J. Therm. Anal. Calorim. 1993, 40, 657-667. [CrossRef]

8. Yu, F.M.; Lu, A.; Lu, J.L.; Wang, Z.Y.; Zhang, Q.; Geng, C.Z.; Li, Z.M. Effect of phenyl content, sample thickness and compression on damping performances of silicone rubber: A study by dynamic mechanical analysis and impact damping test. Polym. Test. 2019, 80, 106101. [CrossRef]

9. Palma, M.D.; Marchi, T.; Carturan, S.; Checchia, C. Pulse shape discrimination in polysiloxane-based liquid scintillator. IEEE Trans. Nucl. Sci. 2016, 63, 1608-1615.

10. Quaranta, A.; Carturan, S.M.; Marchi, T.; Kravchuk, V.L.; Gramegna, F.; Maggioni, G.; Degerlier, M. Optical and scintillation properties of polydimethyl-diphenylsiloxane based organic scintillators. IEEE Trans. Nucl. Sci. 2010, 57, 891-900. [CrossRef] 
11. Palma, M.D.; Carturan, S.M.; Degerlier, M.; Marchi, T.; Cinausero, M.; Gramegna, F.; Quaranta, A. Non-toxic liquid scintillators with high light output based on phenyl-substituted siloxanes. Opt. Mater. 2015, 42, 111-117. [CrossRef]

12. Rubio, A.; Freire, J.J.; Piérda Inés, F. Excimer-Forming Sites of Poly(methylphenylsiloxane). Macromolecules 1989, 22, 4014-4019. [CrossRef]

13. Horta, A.; Pie'rola, I.F.; Macanita, A.L. Molecular dynamics of methylphenylsiloxane chains. Macromolecules 2000, 33, 1213-1223. [CrossRef]

14. Dias, F.B.; Lima, J.C.; Macanita, A.L.; Clarson, S.J.; Horta, A.; Pie'rola Ine's, F. Anomalous fluorescence of linear poly(methylphenylsiloxane) in dilute solution at temperatures below $-50^{\circ} \mathrm{C}$. Macromolecules 2000, 33, 4772-4779. [CrossRef]

15. Shang, Y.R.; Zhang, X.X.; Xu, H.; Li, J.Q.; Jiang, S.C. Microscopic study of structure/property interrelation of amorphous polymers during uniaxial deformation: A molecular dynamics approach. Polymer 2015, 77, 254-265. [CrossRef]

16. Nam, K.H.; Choi, H.K.; Yeo, H.; You, N.H.; Ku, B.C.; Yu, J. Molecular design and property prediction of sterically confined polyimides for thermally stable and transparent materials. Polymers 2018, 10, 630. [CrossRef]

17. Guseva, D.V.; Rudyak, V.Y.; Komarov, P.V.; Bulgakov, B.A.; Babkin, A.V.; Chertovich, A.V. Dynamic and static mechanical properties of crosslinked polymer matrices: Multiscale simulations and experiments. Polymers 2018, 10, 792. [CrossRef]

18. Dalgakiran, E.; Tatlipinar, H. The role of hydrophobic hydration in the LCST behaviour of POEGMA300 by all-atom molecular dynamics simulations. Phys. Chem. Chem. Phys. 2018, 20, 15389-15399. [CrossRef]

19. Fu, K.; Xie, Q.; LÜ, F.C.; Duan, Q.J.; Wang, X.J.; Zhu, Q.S.; Huang, Z.Y. Molecular dynamics simulation and experimental studies on the thermomechanical properties of epoxy resin with different anhydride curing agents. Polymers 2019, 11, 975. [CrossRef]

20. Shen, J.X.; Lin, X.S.; Liu, J.; Li, X. Effects of cross-link density and distribution on static and dynamic properties of chemically cross-linked polymers. Macromolecules 2019, 52, 121-134. [CrossRef]

21. DasSk, A.; Ali, M. Molecular dynamics simulation studies on structure, dynamics, and thermodynamics of uranyl nitrate solution at various acid concentrations. J. Phys. Chem. B 2019, 123, 4571-4586.

22. Bahar, I.; Zuniga, I.; Dodge, R.; Mattice, W.L. Conformational statistics of poly(dimethylsiloxane). 1.Probability distribution of rotational isomers from molecular dynamics simulations. Macromolecules 1991, 24, 2986-2992. [CrossRef]

23. Freire, J.J.; Pie'rola, I.F.; Horta, A. Conformational analysis of methyl-phenyl-siloxane chains. Macromolecules 1996, 29, 5143-5148. [CrossRef]

24. Neuburger, N.; Bahar, I.; Mattice, W.L. Molecular dynamics simulations of poly(dialkylsi1oxanes).Conformational statistics and unperturbed chain dimensions. Macromolecules 1992, 25, 2447-2454. [CrossRef]

25. Kurbatov, A.O.; Balabaev, N.K.; Mazo, M.A.; Kramarenko, E.Y. Molecular dynamics simulations of single siloxane dendrimers: Molecular structure and intramolecular mobility of terminal groups. J. Chem. Phys. 2018, 148, 014902. [CrossRef]

26. Sethi, S.K.; Soni, L.; Manik, G. Component compatibility study of poly(dimethyl siloxane) with poly(vinyl acetate) of varying hydrolysis content: An atomistic and mesoscale simulation approach. J. Mol. Liq. 2018, 272, 73-83. [CrossRef]

27. Klonos, P.; Bolbukh, Y.; Koutsiara, C.S.; Zafeiris, K.; Kalogeri, O.D.; Sternik, D.; Marczewska, A.D.; Tertykh, V.; Pissis, P. Morphology and molecular dynamics investigation of low molecular weight PDMS adsorbed onto Stöber, fumed, and sol-gel silica nanoparticles. Polymer 2018, 148, 1-13. [CrossRef]

28. Trazkovich, A.J.; Wendt, M.F.; Hall, L.M. Effect of Copolymer Sequence on Local Viscoelastic Properties near a Nanoparticle. Macromolecules 2019, 52, 513-527. [CrossRef]

29. Zlatanic, A.; Radojcic, D.; Wan, X.M.; Messman, J.M.; Dvornic, P.R. Monitoring of the Course of the Silanolate-Initiated Polymerization of Cyclic Siloxanes. A Mechanism for the Copolymerization of Dimethyl and Diphenyl Monomers. Macromolecules 2018, 51, 895-905. [CrossRef]

30. Babu, G.N.; Christopher, S.S.; Newmark, R.A. poly(dimethylsiloxane-co-diphenylsiloxanes): Synthesis, characterization, and sequence analysis. Macromolecules 1987, 20, 2654-2659. [CrossRef] 
31. Brewer, J.R.; Tsuchihara, K.; Morita, R. Poly(diethylsiloxane-co-diphenylsiloxane) and poly(diethylsiloxane-co3,3,3-trifluoropropylmethylsiloxane): Synthesis, characterization and low-temperature properties. Polymer 1994, 35, 5109-5117. [CrossRef]

32. Brewer, J.R.; Tsuchihara, K.; Morita, R. Poly(diethylsiloxane-co-ethylphenylsiloxane) and poly(diethylsiloxane-co- methylphenylsiloxane): Synthesis and characterization. Polymer 1994, 35, 5118-5123. [CrossRef]

33. Ziemelis, M.J.; Saam, J.C. Sequence distribution in poly(dimethylsiloxane-co-methylvinylsiloxanes). Macromolecules 1989, 22, 2111-2116. [CrossRef]

34. Harwood, H.J.; Ritchey, W.M. The characterization of sequence distribution in copolymers. J. Polym. Sci. B Polym. Lett. 1964, 2, 601-607. [CrossRef]

35. Jancke, H.; Engelhardt, G.; Kriegsmann, H. Quantitative Mikrostrukturanalyse von siloxankopolymeren mit hilfe der 29 Si-NMR-spectroskopie. Plaste Kautsch. 1979, 26, 612-613.

36. Engelhardt, G.; Jancke, H. Structure investigation of organosilicon polymers by silicon-29 NMR. Polym. Bull. 1981, 5, 577-584. [CrossRef]

37. Okada, O.; Oka, K.; Kuwajima, S.; Toyoda, S.; Tanabe, K. Molecular simulation of an amorphous poly(methyl methacrylate)-poly(tetrafluoroethylene) interface. Comput. Theor. Polym. Sci. 2000, 10, 371-381. [CrossRef]

38. Luo, Z.L.; Jiang, J.W. Molecular dynamics and dissipative particle dynamics simulations for the miscibility of poly(ethylene oxide)/poly(vinyl chloride) blends. Polymer 2010, 51, 291-299. [CrossRef]

39. Makrodimitri Zoi, A.; Dohrn, R.; Economou, I.G. Atomistic simulation of poly(dimethylsiloxane): Force field development, structure, and thermodynamic properties of polymer melt and solubility of n-alkanes, n-perfluoroalkanes, and noble and light Gases. Macromolecules 2007, 40, 1720-1729. [CrossRef]

40. Smith, J.S.; Borodin, O.; Smith, G.D. A quantum chemistry based force field for poly(dimethylsiloxane). J. Phys. Chem. B 2004, 108, 20340-20350. [CrossRef]

41. Choi, J.; Yu, S.; Yang, S.; Cho, M. The glass transition and thermoelastic behavior of epoxy-based nanocomposites: A molecular dynamics study. Polymer 2011, 52, 5197-5203. [CrossRef]

42. Trady, S.; Mazroui, M.; Hasnaoui, A.; Saadouni, K. Molecular dynamics study of atomic-level structure in monatomic metallic glass. J. Non-Cryst. Solids 2016, 443, 136-142. [CrossRef]

43. Mohammdi, M.; Fazli, H.; karevan, M.; Davoodi, J. The glass transition temperature of PMMA: A molecular dynamics study and comparison of various determination methods. Eur. Polym. J. 2017, 91, 121-133. [CrossRef]

44. Klonos, P.A. Crystallization, glass transition, and molecular dynamics in PDMS of low molecular weights: A calorimetric and dielectric study. Polymer 2018, 159, 169-180. [CrossRef]

45. Liu, B.Z.; Gao, X.Y.; Zhao, Y.F.; Dai, L.N.; Xie, Z.M.; Zhang, Z.J. 9,10-Dihydro-9-oxa-10-phosphaphenanthrene 10-oxide-based oligosiloxane as a promising damping additive for methyl vinyl silicone rubber (VMQ). J. Mater. Sci. 2017, 52, 8603-8617. [CrossRef]

46. Cvek, M.; Mrlík, M.; Ilčíková, M.; Mosnáček, J.; Münster, L.; Pavlínek, V. Synthesis of silicone elastomers containing silyl-based polymer-grafted carbonyl iron particles: An efficient way to improve magnetorheological, damping, and sensing performances. Macromolecules 2017, 50, 52189-52200. [CrossRef]

47. Cabanelas, J.C.; Serrano, B.; Gonzalez, M.G.; Baselga, J. Confocal microscopy study of phase morphology evolution in epoxy/polysiloxane thermosets. Polymer 2005, 46, 6633-6639. [CrossRef]

48. Han, T.; Gui, C.; Lam, J.W.Y.; Jiang, M.J.; Xie, N.; Kwok, R.T.K.; Tang, B.Z. High-contrast visualization and differentiation of microphase separation in polymer blends by fluorescent AIE probes. Macromolecules 2017, 50, 5807-5815. [CrossRef]

(C) 2019 by the authors. Licensee MDPI, Basel, Switzerland. This article is an open access article distributed under the terms and conditions of the Creative Commons Attribution (CC BY) license (http://creativecommons.org/licenses/by/4.0/). 